\title{
Research on Information Spillover Effect of the RMB Exchange Rate and Stock Market Based on R-Vine Copula
}

\author{
Xiaofei Wu (iD, Shuzhen Zhu (iD, and Suxue Wang (iD \\ Glorious Sun School of Business and Management, Donghua University, Shanghai 200050, China \\ Correspondence should be addressed to Xiaofei Wu; 1152074@mail.dhu.edu.cn
}

Received 3 April 2020; Accepted 24 April 2020; Published 18 May 2020

Guest Editor: Benjamin Miranda Tabak

Copyright ( 2020 Xiaofei Wu et al. This is an open access article distributed under the Creative Commons Attribution License, which permits unrestricted use, distribution, and reproduction in any medium, provided the original work is properly cited.

\begin{abstract}
This paper studies the dependence structure and information spillover effect between the RMB exchange rate and the Chinese stock market based on the R-vine copula model and spillover index model. The results show that due to the occurrence of the trade war, the correlation between the three RMB exchange rate indicators and the two stock market indicators increases in varying degrees. In the intensity of spillover, the information spillover of the stock market to the RMB exchange rate is significantly enhanced, and the information spillover intensity of the RMB Index to the stock market increases, but the information spillover of the US dollar and Hong Kong dollar exchange rates to the stock market is significantly weakened. In the direction of spillover, the spillover of the RMB Index and stock market shows the characteristics of alternating transformation, while the exchange rate of a single currency and the stock market shows a one-way transmission from the stock market to the exchange rate. Additionally, the information spillover between the RMB exchange rate and the stock market is closely related to the degree of market openness. The RMB Index contains more information than the exchange rate of a single currency.
\end{abstract}

\section{Introduction}

With the financial globalization and complex environment, not only the RMB foreign exchange market fluctuates abnormally but also the Chinese stock market fluctuates violently and the exchange rate market fluctuates frequently. China's economy has suffered as a result of the successful implementation of supply-side reforms and financial deleveraging. The current economy has gradually recovered, but there is still a huge difference compared with the launch of the US tax reform policy and the full recovery of the economy. The serious economic differentiation between the two countries has led to the fluctuation of the RMB exchange rate to a certain extent. In addition, in recent years, in order to reduce the trade deficit and environmental domestic deficit pressure, the United States has directly referred to China as a "currency manipulator." A trade war broke out between the United States and China, and although the first phase of the trade agreement between the two countries has been agreed, the escalating "tariff war" has caused some damage to the economies and financial markets of the two countries, the profits of related industries, and the average price-to-earnings ratio.

Regarding the Sino-US trade war as a typical shock, this paper studies the correlation and information spillover effects between the RMB exchange rate and stock markets to show the dynamic changes of their relationship. The process of domestic exchange rate system reform and RMB internationalization has improved the degree of marketization and openness of the exchange rate, and its relationship with the stock market is becoming more and more complex. Studying the impact of trade conflict on information transmission between the two markets is helpful to supplement or support previous conclusions. Further exploration of the path and direction of potential risk transmission can provide a basis for risk management and control for national authorities and investors.

The structure of the paper is as follows. Section 2 is a review of the related literature. The selected model specifications and related methodology are provided in Section 3 . We apply the model specifications to study the information overflow of the RMB exchange rates and the stock 
market in Section 4. Finally, the main conclusions are drawn in Section 5.

\section{Literature Review}

The research on the RMB exchange rate and stock market mainly focuses on their correlation and spillover effect. Traditional measurement methods included the correlation coefficient method, Granger causality test, GARCH family model, and so on. With the development of the theory, more models have appeared and been popularized. Copula function has become a widely used tool to measure the correlation of variables because it did not limit edge distribution and can capture nonlinear asymmetry and tail relation effectively. With the deepening of research and the increase of research variables, binary copula function can no longer meet the needs of research. Joe and $\mathrm{Hu}$ [1] proposed the vine copula model, which can flexibly describe the dependence structure between multiple variables. In recent years, Diebold and Yilmaz [2] proposed a new method, which is based on traditional orthogonal variance decomposition to characterize multivariate information spillovers, enriching the research method system of spillovers. After that, they [3] improved this method again, using the generalized VAR framework to overcome the problem of variable ranking and proposed a method to calculate directional overflow index, net overflow index, and pair of net overflow indexes. With the help of constantly improving and perfecting measurement methods, the research on the exchange rate and the stock market is also advancing. As foreign markets are relatively open, cross-market research was relatively mature. The research focused on two issues. The first issue was whether and how exchange rates are related to the stock market. Nieh and Lee [4] found that in the long run, there was no significant correlation between stock prices and exchange rates in G-7 countries. Tudor and Popescu-Dutaa [5] compared 13 developed and emerging financial markets and found that there was a significant Granger causality between stock price and exchange rate. Andreou et al. [6] studied 12 emerging markets; it was found that the two markets have significant two-way impacts. Blau [7] studied the influence of euro on relevant stock markets; he found that a stable exchange rate was conducive to the stability of stock markets and reduced the possibility of stock market bubbles. Blau [8] found that the US exchange rate and stock market were linked through fluctuations in US depositary receipts. The second issue was whether there were time-varying effects and structural changes in the correlation between the exchange rate and the stock market. Relevant studies showed that such changes were usually related to market conditions and external shocks. Śmiech and Papież [9] found that during the financial crisis and high market volatility, the correlation between exchange rates and stock markets in European countries has increased. Sui and Sun [10] also supported that the crisis will also strengthen the link between stock and foreign exchange markets in emerging countries. Reboredo et al. [11] studied the different states of exchange markets and stock markets in eight emerging economies and found that the correlation shows asymmetric effects in the upward and downward phases of the market.

In China, research on the exchange rate and stock market revolves around four aspects. The first was the correlation between the exchange rate and stocks in different sectors. Yin [12] focused on the study of the interconnection between specific industries and the RMB exchange rate. It was found that the exchange rate has a positive impact on the marginal risk spillover of related industries at any risk level, and the impact degree of each industry was different. Zhao and Shi [13] improved their research on various sectors of the stock market, including Shanghai Stock, Shenzhen Stock, and small and medium-sized stocks. It was found that the three markets were affected by exchange rates to different degrees. The research of Yu et al. [14] also found that there were industry differences in the relationship between the stock market and exchange rate (Supplementary Materials available here). The second was the correlation between different exchange rate indexes and the stock market. Previous studies have mostly focused on onshore RMB and were lacking focus on offshore RMB. Zhou and Han [15] and Que and Li [16] have made improvements in this aspect. Among them, Zhou's research made the comparison between onshore and offshore RMB's spillover effects on stock market risks, while Que's research paid attention to the spillover effects of interest rate spread on the stock market. The third was cross-market correlation research. Chen et al. [17] expanded the market and studied the relationship among the foreign exchange market, bond market, and stock market to fill the gap of a cross-market investment portfolio. It was found that among the interaction of the three, the stock market and foreign exchange market were more closely linked. Xiao and Yin [18] believed that the foreign exchange market was relatively separated from the bond market, but it has a significant fluctuation effect with the stock market. Zhang's research [19] showed that the impact of the stock market on the exchange rate was more in the long term, while the impact of the exchange rate on the "triple paradox" mechanism of the stock market through interest rate transmission was limited. The fourth was the study of the exchange rate and stock market under different market conditions and external shocks. Wang et al. [20] found that the relationship between the two markets was related to market conditions. There was a significant asymmetric twoway volatility spillover effect under bull market conditions. In the bear market, there was the only one-way overflow of the stock market to the foreign exchange market. Important events such as financial crisis and policy reform usually lead to structural changes in the relationship between the two. Yan and $\mathrm{Li}$ [21] found that the crisis changed the spillover of the exchange market to the stock market into the stock market to the exchange market, and there were no significant mean spillover and volatility spillover effects during the crisis. Hao and $\mathrm{Li}$ [22] focused on studying the impact of the international stock market and the RMB exchange rate on China's stock market through the analysis of plummeting events. The results showed that the impact of the RMB exchange rate on China's stock market in the context of devaluation has only weak supporting evidence. Research by Chen and Liu [23] showed that RMB's accession to the SDR basket will lead to 
the expected appreciation of the exchange rate, thus having a positive effect on the A-H share premium. Liang and Zhang [24] found that the A-share market was increasingly affected by RMB under the background of the trade war. The devaluation of RMB will lead to the decline of the stock market and affect the safety of capital. Li et al. [25] believed that the influence of the RMB exchange rate on the stock market comes from the short-term arbitrage capital flow caused by investor expectations.

In the complex international environment, this paper did improvements and innovations in the following three aspects. Firstly, from the perspective of the research background, we select the data of the Sino-US trade war period, which is different from mature research under the background of the subprime mortgage crisis and economic crisis. The aim is to explore the dynamic changes of the relationship between the exchange rate and stock market, providing a scientific basis for national risk transmission prevention and investor hedging measures. Secondly, from the perspective of research content, previous studies have mostly focused on the correlation or spillover effect, while there are few works of literature that combine the two sides. Using the vine copula model to explore the correlation structure between the two sides and studying the direction and intensity of information spillover can make the research more extensive. Thirdly, from the perspective of research methods, vine copula and spillover index models are relatively advanced research technologies, which are more effective in depicting the dependency relationship and spillover structure of multidimensional variables. They complement and support each other to obtain more reliable and rigorous conclusions.

\section{Model Building}

3.1. GARCH $(1,1)$ Model of the Marginal Distribution. Before vine copula modeling, the edge distribution of each sequence should be fitted. The sequence is tested by autocorrelation and $\mathrm{ARCH}$ effect. Considering the fluctuation aggregation effect of variables, GARCH $(1,1)$ model and $t$ distribution are introduced to fit variables. The specific mathematical formula is as follows:

$$
\begin{aligned}
r_{t} & =\mu+a_{t}, \\
\sigma_{t}^{2} & =\omega+\alpha a_{t-1}^{2}+\beta \sigma_{t-1}^{2}, \\
a_{t} & =\sigma_{t} \varepsilon_{t}, \\
\varepsilon_{t} & \sim \text { i.i.d.t. }
\end{aligned}
$$

Among them, $r_{t}$ represents the rate of return, $\sigma_{t}$ represents the conditional variance, $a_{t}$ is the residual sequence, and $\varepsilon_{t}$ is the standardized residual, where $t$ is the standard distribution with mean 0 and variance 1 . The parameters to be evaluated are $\mu, \omega, \alpha$, and $\beta$.

3.2. The Vine Copula Model. Copula theory was first proposed by Sklar in 1959 and has been widely used in the financial field since then. Its essence is a connection function, which combines the joint distribution function with the edge distribution of variables. According to Sklar's theorem, if $X$ is an $n$-dimensional random vector like $X=\left(X_{1}, X_{2}, \ldots, X_{n}\right)$, then $F\left(x_{1}, x_{2}, \ldots, x_{n}\right)=C\left(F\left(x_{1}\right)\right.$, $\left.F\left(x_{2}\right), \ldots, F\left(x_{n}\right)\right)$, where $F\left(x_{1}, x_{2}, \ldots, x_{n}\right)$ is a joint distribution function. $F\left(x_{n}\right)$ is an edge distribution function of the $n$th variable, and $\mathrm{C}$ is a copula connection function. If the edge distribution function is continuous, then the copula function is unique. Common copula functions include Gaussian copula, $t$ copula, Archimedes copula (including Gumbel copula and Clayton copula).

With the constant increase of variables, the original copula technology cannot be satisfied. In 1996, Joe proposed a vine structure to connect the pairwise dependencies of multiple variables and expand the scope of application of copula, which is called the vine copula model. The first two vine structure copulas proposed are $\mathrm{C}$-vine copula and $\mathrm{D}$-vine copula. The difference between the two is that the form of $\mathrm{C}$-vine takes one of the variables as the root node, and the other variables are connected to it, while D-vine is connected in two by two according to the order between the variables. Subsequently, a new vine structure, called R-vine, was developed on the basis of $\mathrm{C}$-vine and $\mathrm{D}$-vine. It combines the characteristics of $\mathrm{C}$-vine and $\mathrm{D}$-vine and can have more than one root node. Its advantage is that when the number of variables is large, the R-vine copula model is more effective.

The concept of R-vine was proposed by Bedford and Cooke. Kurowicka and Cooke gave a detailed description that an $n$-variable R-vine consists of $(n-1)$ trees and is denoted as $T_{1}, T_{2}, \ldots, T_{n-1}$, the node set of tree $T_{i}$ is $N_{i}$, and the edge set is $E_{i}(i=1, \ldots, n-1)$, which satisfy the following conditions:

(i) Node set $N_{1}=\{1, \ldots, n\}$ and edge set $E_{1}$ of tree $T_{1}$.

(ii) The node set $N_{i}=E_{i-1}(i=2, \ldots, n-1)$ of tree $T_{i}$; it means that the node set of tree $i$ is the edge set of tree $i-1$.

(iii) If two edges in the tree $T_{i}$ are connected by edges in the tree $T_{i+1}$, then the two edges must have a common node in the tree $T_{i}$.

The $\mathrm{R}$-vine with 5 variables and 4 trees constructed according to the above conditions is shown in Figure 1.

In order to establish R-vine copula model for $N$ variables, we mark the node as $N=\left\{N_{1}, \ldots, N_{n-1}\right\}$, the edge is $E=\left\{E_{1}, \ldots, E_{n-1}\right\}$, and one of the edges in $E_{i}$ is $e=j(e), k(e) \mid D(e)$, where $j(e)$ and $k(e)$ are two conditional nodes associated with edge $e, D(e)$ is the conditional set, and $c_{j(e), k(e) \mid D(e)}$ is the corresponding copula density function. Suppose that an $n$-dimensional random variable $X=\left(X_{1}, \ldots, X_{n}\right), X_{D(e)}$ is a subvector of $X$ determined by condition set $D(e)$, and the marginal density of the $k$-th variable $X_{k}$ is $f_{k}(k=1, \ldots, n)$. Then, an R-vine distribution can be defined as the joint probability density function $f\left(x_{1}, \ldots, x_{n}\right)$ of the random vector $X=\left(X_{1}, \ldots, X_{n}\right)$, as shown in the following formula: 


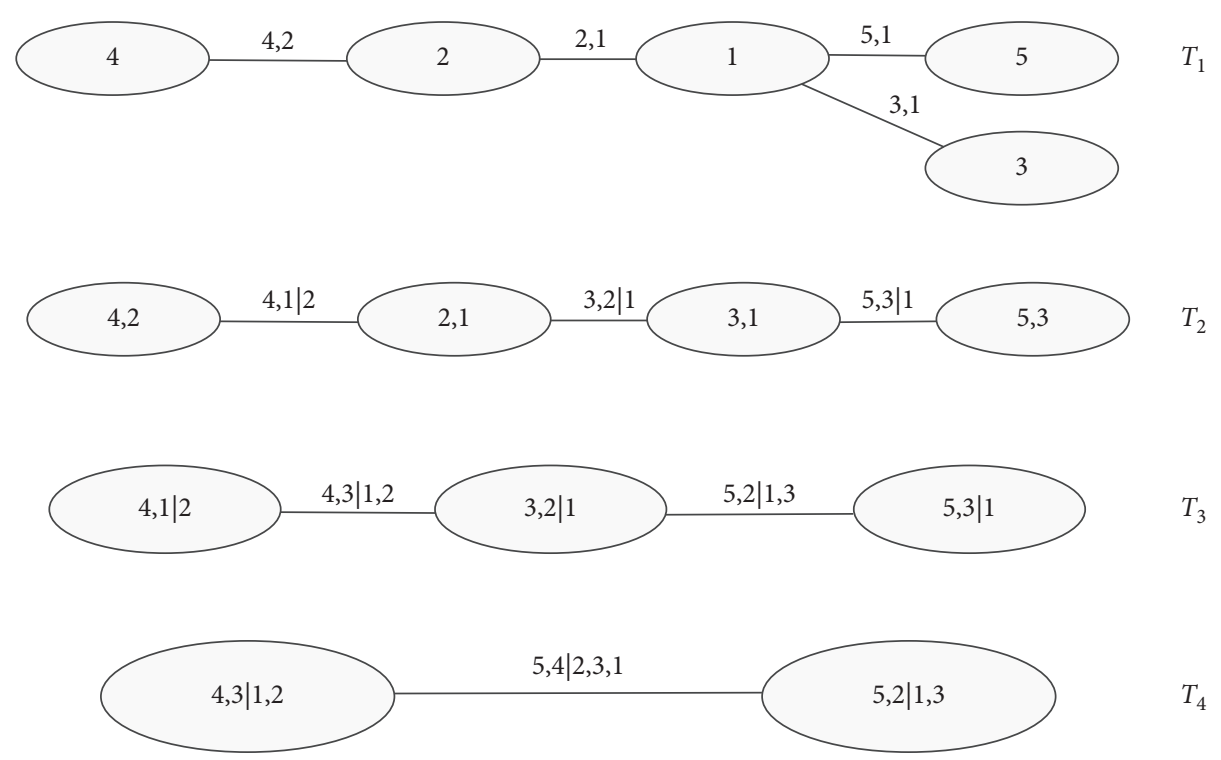

FIGURE 1: R-vine structure with five variables.

$$
\begin{aligned}
f\left(x_{1}, x_{2}, \ldots, x_{n}\right)= & \prod_{k=1}^{n} f_{k}\left(x_{k}\right) \cdot \prod_{i=1}^{n-1} \prod_{e \in E_{i}} c_{j(e), k(e) \mid D(e)} \\
& \cdot\left(F\left(x_{j(e)} \mid x_{D(e)}\right), F\left(x_{k(e)} \mid x_{D(e)}\right)\right) .
\end{aligned}
$$

3.3. Information Spillover Index Model. The information spillover index model proposed by Diebold and Yilmaz is constructed as follows. Firstly, we construct an n-dimensional $\operatorname{VAR}(P)$ model with stable covariance: $X_{t}=$ $\sum_{i=1}^{p} \Phi_{i} X_{t-i}+\varepsilon_{t}$, where $\varepsilon_{t} \sim(0, \Sigma)$ is an independent and identically distributed vector. Its moving average process is $X_{t}=\sum_{i=0}^{\infty} A_{i} \varepsilon_{t-i}$; here $A_{i}$ is the coefficient matrix of $N * N$ and satisfies the recurrence formula: $A_{i}=\Phi_{1} A_{i-1}+$ $\Phi_{2} A_{i-2}+\cdots+\Phi_{p} A_{i-p}$, where $A_{0}$ is the $n$-order unit matrix. If $i<0$, then $A_{i}=0$. The coefficient of the moving average equation is the determining factor of the system change and the variance decomposition result.

Diebold and Yilmaz define their variance decomposition as the part of the $H$-step prediction error variance of the variable $X_{i}$ that is impacted by themselves and volatility spillover as the part of the $H$-step prediction error variance of the variable $X_{i}$ that is impacted by other variables. According to the above theory, the $H$-step prediction error variance under the generalized VAR framework is decomposed into

$$
\theta_{i j}^{g}(H)=\frac{\sigma_{j j}^{-1} \sum_{h=0}^{H-1}\left(e_{i}^{\prime} A_{h} \sum e_{j}\right)^{2}}{\sum_{h=0}^{H-1}\left(e_{i}^{\prime} A_{h} \sum A_{h}^{\prime} e_{i}\right)},
$$

where $H=1,2, \ldots, \Sigma$ is the variance matrix of the error vector $\varepsilon, \sigma_{j j}$ is the standard deviation of the error term of the $j$-th equation, $e_{i}$ is the selection vector, and the other elements are zero except the value of the $i$-th element which is 1 . Since the information impact of variables under the generalized VAR framework is not orthogonal, it is necessary to standardize each variance decomposition matrix. The standardized formula is

$$
\tilde{\theta}_{i j}^{g}(H)=\frac{\theta_{i j}^{g}(H)}{\sum_{j=1}^{N} \theta_{i j}^{g}(H)} .
$$

According to the method of calculating volatility contribution by difference decomposition under the generalized VAR framework, the total volatility spillover index can be constructed to characterize the contribution of the volatility spillover effect of each variable to the variance of total prediction error. The calculation formula is

$$
S^{g}(H)=\frac{\sum_{\substack{i, j=1 \\ i \neq j}}^{N} \tilde{\theta}_{i j}^{g}(H)}{\sum_{i, j=1}^{N} \tilde{\theta}_{i j}^{g}(H)} \cdot 100=\frac{\sum_{\substack{i, j=1 \\ i \neq j}}^{N} \tilde{\theta}_{i j}^{g}(H)}{N} \cdot 100 .
$$

In addition to the total spillover index, the generalized VAR model can also analyze the direction of the spillover effect of each variable. The standardized formula for calculating the directional spillover effect of the variable $j$ on the variable $i$ is

$$
S_{i .}^{g}(H)=\frac{\sum_{j=1}^{N} \tilde{\theta}_{i j}^{g}(H) \quad}{\sum_{i, j=1}^{N} \widetilde{\theta}_{i j}^{g}(H)} \cdot 100=\frac{\sum_{j=1}^{N} \widetilde{\theta}_{i j}^{g}(H)}{N} \cdot 100 .
$$

Correspondingly, the directional fluctuation overflow of the variable $i$ to the variable $j$ is 


$$
S_{\cdot i}^{g}(H)=\frac{\sum_{\substack{j=1 \\ j \neq i}}^{N} \tilde{\theta}_{j i}^{g}(H) \quad}{\sum_{i, j=1}^{N} \tilde{\theta}_{j i}^{g}(H)} \cdot 100=\frac{\sum_{\substack{j \neq 1 \\ j \neq i}}^{N} \widetilde{\theta}_{j i}^{g}(H)}{N} \cdot 100 .
$$

According to the above two-directional spillover effects, the net fluctuation spillover effect can be calculated. The net fluctuation spillover effect of the variable $i$ on other variables is

$$
S_{i}^{g}(H)=S_{\cdot i}^{g}(H)-S_{i .}^{g}(H) .
$$

In actual application, the fluctuation spillover effect between the two variables is often more important. Diebold and Yilmaz [3] define it as

$$
\begin{aligned}
S_{i j}^{g}(H) & =\left(\frac{\tilde{\theta}_{j i}^{g}(H)}{\sum_{i, k=1}^{N} \widetilde{\theta}_{i k}^{g}(H)}-\frac{\tilde{\theta}_{i j}^{g}(H)}{\sum_{j, k=1}^{N} \tilde{\theta}_{j k}^{g}(H)}\right) \cdot 100 \\
& =\left(\frac{\widetilde{\theta}_{j i}^{g}(H)-\widetilde{\theta}_{i j}^{g}(H)}{N}\right) \cdot 100 .
\end{aligned}
$$

\section{Results and Discussion}

In this section, we select the representative variables of the $\mathrm{RMB}$ exchange rate and the Chinese stock market. Based on R-vine, the variables construct a vine copula model to obtain the dependence structure. The dynamic and static analysis method of the information overflow index model is used to obtain the overflow direction and intensity between variables, especially between two variables. Based on the above two methods, this paper describes the interdependence and information spillover structure between the RMB exchange rate and the stock market during the Sino-US trade war and draws reliable research conclusions.

4.1. Data Description. As the study was carried out against the background of the Sino-US trade war, the USD/CNY index was directly affected by it. The PEG linked exchange rate system has been closely linking the Hong Kong dollar and the US dollar. After several major reforms, the mainland of China has formed a managed floating exchange rate system with reference to a basket of currencies. The exchange rate will be affected by more currencies. Besides, as the connection between the mainland and Hong Kong is gradually established, the combination of the two could better reflect the comprehensiveness and integrity of the study. Based on the above background, we will select the variables of USD/CNY, HKD/CNY, RMB Index, Shanghai and Shenzhen 300 Index, and Hong Kong Hang Seng Index. The data come from the Choice database. The research period is from July 4, 2016, to January 17,2020 . Inconsistent factors such as holidays are eliminated and relevant pretreatment is carried out. The logarithmic rate of return of the variable is calculated as follows:

$$
r_{i, t}=\ln \left(\frac{p_{i, t}}{p_{i, t-1}}\right),
$$

where $r_{i, t}$ is the logarithmic rate of return of variable $i$ on day $t$ and $p_{i, t}$ is the price of the variable $i$ on day $t$.

Table 1 shows the descriptive statistics of variables. According to the maximum, minimum, and standard deviation, the stock market fluctuates most strongly, the RMB Index fluctuates second, and USD/CNY and the HKD/CNY fluctuate the least. Among them, the volatility of the mainland stock market is higher than that of the Hong Kong stock market. Judging from skewness and kurtosis, we find that all sequences have a peak and thick tail. In addition, the $\mathrm{ADF}$ test shows that the sequences are stationary, and we can conduct further modeling and analysis.

4.2. Fitting Result of Edge Distribution. Autocorrelation test, ARMA modeling, and the ARCH test are carried out on the sequences. It is found that the sequences have an $\mathrm{ARCH}$ effect. Therefore, the GARCH model can be constructed. $\operatorname{GARCH}(1,1)$ is selected here for a fitting. The results are shown in Table 2. The value of $\alpha+\beta$ of CSI300 Index and Hong Kong Hang Seng Index is very close to 1 , which shows that the fluctuation of the Chinese stock market has a continuous effect. In contrast, the volatility of the exchange rate market, especially the RMB Index, is relatively low. The normalized residual series all passed the KS test. The sequences can be modeled and analyzed by vine copula.

4.3. Analysis of the Result of the R-Vine Copula Model. The data obtained by edge distribution fitting are used to make a matrix scatter plot of the dependence between the $\mathrm{RMB}$ exchange rate and the stock market. Among them, the triangular area in the lower-left corner of the matrix is the contour line of each variable, and the upper right corner is the variable scatter plot area and Kendall value between the two variables. A subsample analysis is conducted on March 8,2018 , as an important time point before and after the SinoUS trade war. The scatter plot of the exchange rate and stock market before and during the trade war is shown in Figure 2. Before the trade conflict occurred, the exchange rate and the stock market operated relatively smoothly. The correlation between the USD/CNY and the HKD/CNY is 0.91 , which shows the exchange rate market is closely linked internally. The two currencies' exchange rate and RMB Index have a correlation coefficient of 0.12 . As a result of the two-market accommodation policy in recent years, the mainland stock market has a strong positive correlation with the Hong Kong stock market. There is a weak correlation between the RMB exchange rate and the stock market, and the correlation between the single currency and the stock market is slightly stronger. With the occurrence of the Sino-US trade war, the USD/CNY frequently fluctuates under pressure. At the same time, the stock market also fluctuates violently, and thus the internal correlation between the exchange rate and the stock market changes. The internal correlation of the RMB exchange rate is weakened, especially the correlation between 
TABLe 1: Descriptive statistics.

\begin{tabular}{|c|c|c|c|c|c|}
\hline & USD/CNY & $\mathrm{HKD} / \mathrm{CNY}$ & RMB & CSI & HSI \\
\hline Mean & $5.65 E-05$ & $5.65 E-05$ & $-2.19 E-05$ & 0.000399 & 0.000440 \\
\hline Maximum & 0.008981 & 0.008855 & 0.014529 & 0.057775 & 0.041251 \\
\hline Minimum & -0.009263 & -0.009330 & -0.019322 & -0.060192 & -0.052519 \\
\hline Standard deviation & 0.002234 & 0.002228 & 0.002308 & 0.010724 & 0.009895 \\
\hline Skewness & -0.141791 & -0.099961 & -0.690067 & -0.017957 & -0.298325 \\
\hline Kurtosis & 4.577832 & 4.447624 & 13.49380 & 6.493369 & 4.736612 \\
\hline JB statistics & $84.381^{* * *}$ & $70.118^{* * *}$ & $3678.1^{* * *}$ & $400.73^{* * *}$ & $110.71^{* * *}$ \\
\hline $\mathrm{ADF}$ value & $-26.667^{* * *}$ & $-26.856^{* * *}$ & $-29.432^{* * *}$ & $-27.979^{* * *}$ & $-27.216^{* * *}$ \\
\hline
\end{tabular}

Note. USD/CNY, HKD/CNY, RMB, CSI, and HSI represent US dollar against RMB, Hong Kong dollar against RMB, RMB Index, Shanghai and Shenzhen 300 Index, and Hong Kong Hang Seng Index, respectively ${ }^{* *},{ }^{* * *}$ Rejection of the null hypothesis at the $5 \%$ and $1 \%$ levels, respectively.

TABLE 2: Estimation results of edge distribution.

\begin{tabular}{|c|c|c|c|c|c|}
\hline & USD/CNY & $\mathrm{HKD} / \mathrm{CNY}$ & $\mathrm{RMB}$ & CSI & HSI \\
\hline$\mu$ & $6.827 e-05$ & $5.4192 e-05$ & $-3.5219 e-06$ & $6.4296 e-04^{* *}$ & $8.0386 e-04^{* *}$ \\
\hline$\omega$ & $9.142 e-08$ & $1.0005 e-07$ & $3.1738 e-06^{* * *}$ & $5.6308 e-07$ & $4.9549 e-07$ \\
\hline$\alpha$ & $1.056 e-01^{* * *}$ & $8.7701 e-02^{* * *}$ & $2.9990 e-01^{* * *}$ & $4.6354 e-02^{* * *}$ & $2.2418 e-02^{* * *}$ \\
\hline$\beta$ & $8.889 e-01^{* * *}$ & $8.9905 e-01^{* * *}$ & $2.1124 e-01$ & $9.5012 e-01^{* * *}$ & $9.7275 e-01^{* * *}$ \\
\hline Shape & $4.998 e+00^{* * *}$ & $6.1725 e+00^{* * *}$ & $3.1192 e+00^{* * *}$ & $5.7682 e+00^{* * *}$ & $6.8393 e+00^{* * *}$ \\
\hline KS test & 0.394145 & 0.180304 & 0.932194 & 0.805889 & 0.810711 \\
\hline
\end{tabular}

Note. ${ }^{* *},{ }^{* * *}$ Rejection of the null hypothesis at the $5 \%$ and $1 \%$ levels, respectively.

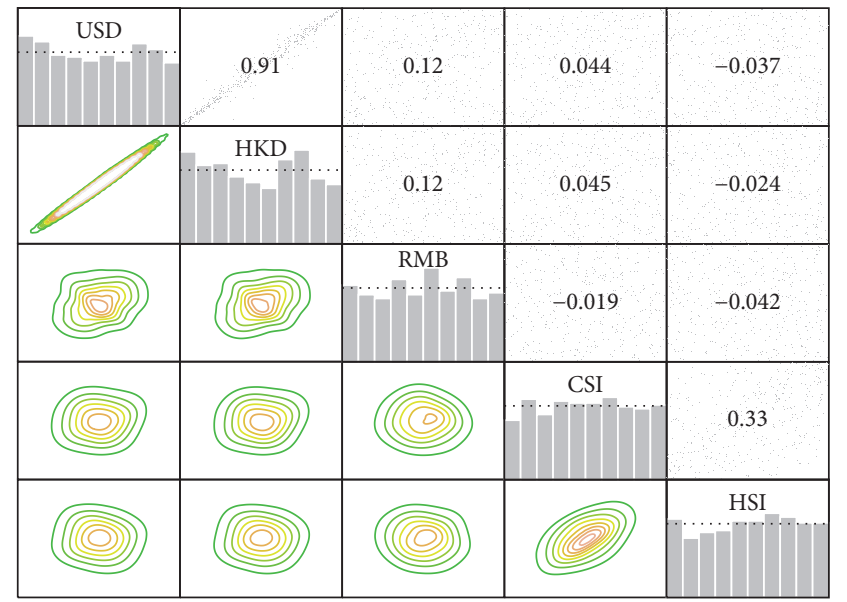

(a)

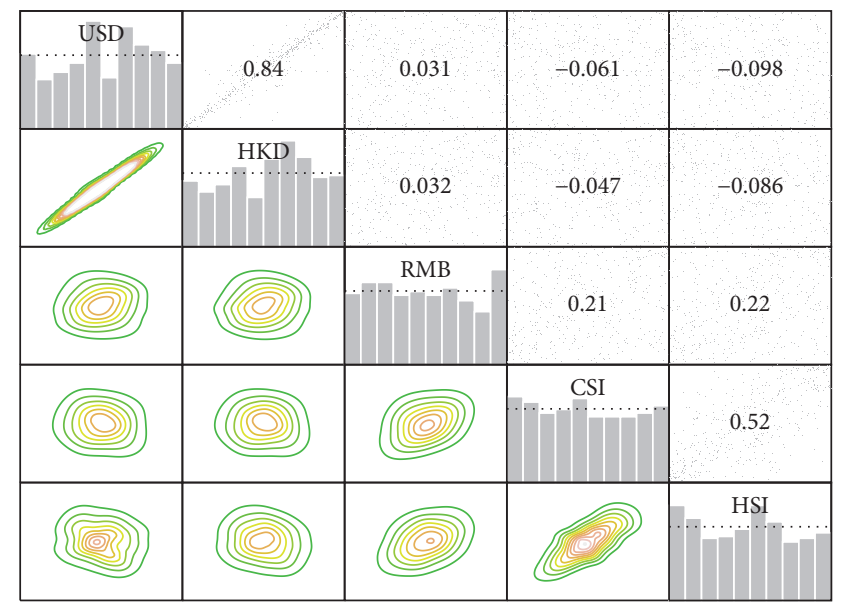

(b)

FIgURE 2: Scatter diagram of dependence matrix. (a) Scatter diagram of two markets before trade war. (b) Scatter diagram of two markets during trade war.

single currency and RMB Index weakened to 0.03 after the trade war. The correlation between the RMB exchange rate and the stock market increased significantly. In addition, the correlation between the US dollar exchange rate, Hong Kong dollar exchange rate, and Shanghai and Shenzhen 300 Index changes from positive to negative, while the correlation between the RMB Index and the stock market changes from negative to positive. Due to the occurrence of external uncertainties, the $\mathrm{RMB}$ exchange rate depreciates rapidly and fluctuates abnormally. In order to maintain the smooth operation of the exchange market, the central bank comprehensively uses various exchange rate tools to deal with the existing unilateral expectation phenomenon. Our governments start the countercyclical adjustment and moderately hedge the procyclical sentiment of currency devaluation.
Under such comprehensive adjustment, the correlation between RMB exchange rates is weakened. Due to the persistence of abnormal fluctuations in one market caused by the trade war, signals are released to other markets, resulting in a significant increase in the correlation between the exchange rate and the stock market. Normally, due to the limited degree of financial market opening, cross-market links are relatively weak. However, under the impact of extreme events, abnormal fluctuations in one market will generate signals and hints to other markets. Market participants will form psychological expectations and change their participation behaviors, leading to market fluctuations. In this process, the correlation between markets will be strengthened. During the Sino-US trade war, the RMB was under devaluation pressure, and the decline in the value of 
the RMB would reduce investor confidence, leading to the outflow of cross-border capital. Coupled with the herding effect, the stock market has a tendency to decline.

Table 3 shows the decomposition results of the "first tree" of R-vine copula, including copula function selection between two variables, parameter value, Kendall value, and tail correlation coefficient. Copula functions include elliptic copula, Archimedes copula, and nonlinear copula functions. It is difficult to accurately describe the different dependency relationships between financial markets with only one specific copula function. Due to the different dependence structures of the two markets, it is necessary to choose the appropriate copula function to describe the correlation between the markets. According to the AIC criterion to judge the effect of the fitting, R-vine chooses the best copula function, including student $t$ copula, Joe copula, Gaussian copula, and Survival BB1 copula function. Gaussian copula could not characterize the tail, while student $t$-copula has symmetrical upper and lower tails. Joe copula is Archimedes copula function, which is suitable for describing the correlation of the upper tail. Before the SinoUS trade war, Joe copula function was used to study the Shanghai and Shenzhen 300 Index and HKD/CNY. The upper tail is 0.13 . It indicates that during the market rise, the correlation between CSI300 and HKD/CNY shows a strong positive spillover effect. During this period, the exchange rate has become more market-oriented and internationalized through reform. The Shanghai-Hong Kong Stock Connect and Shenzhen-Hong Kong Stock Connect mechanisms provide funds for the stock market. Both markets are in a relatively positive condition, so they respond to good news more obviously. Survival BB1 copula is a two-parameter copula model, which combines Clayton copula and Gumbel copula and rotates $180^{\circ}$. It can capture many types of asymmetric dependent structures of upper and lower tails between variables. During the Sino-US trade war, the upper tail between Hong Kong's Hang Seng Index and RMB Index is 0.01 , and the lower tail is 0.21 . The lowertail coefficient is greatly higher than the upper-tail coefficient, indicating that the correlation between Hong Kong stocks and the RMB Index is stronger in the period of market decline than in the period of market rise. The uncertainty of the relationship between the two countries enables the upper and lower tails to show obvious asymmetry and is more sensitive to bad news. The implementation of relevant policies directly leads to abnormal fluctuations in the exchange rate market and the stock market. Bad news can easily lead to investor panic and risk contagion.

The vine copula model is constructed for variables, and different copula functions are used for fitting to obtain a corresponding tree structure diagram, as shown in Figure 3. $\mathrm{R}$-vine contains a series of trees, and each side of each tree corresponds to a (conditional) pair-copula. The transition of the central node based on R-vine is used to analyze the dependence structure between the RMB exchange rate and the stock market. The results are shown in Figures 3(a) and 3 (b), respectively. Before the trade war, the HKD/CNY was at the center of linking the exchange rate market and the stock market, which was directly related to the USD/CNY, the RMB Index, and the Shanghai and Shenzhen 300 Index. If the HKD/CNY fluctuates sharply, the USD/CNY will also fluctuate because the correlation between them is 0.91 . According to Table 3, the upper tail correlation between the Shanghai and Shenzhen 300 Index and the HKD/CNY is relatively high, so the fluctuation of the HKD/CNY will also lead to the fluctuation of the Shanghai and Shenzhen 300 Index. During the trade war, the central variable changes into Hong Kong's Hang Seng Index, which indicates that it plays a leading role in the market linkage. It has a strong lower tail correlation with the RMB Index. If there is a crisis in the Hong Kong stock market, risks will spread from the Hong Kong stock market to the RMB Index, further leading to a decline in the value of the RMB.

4.4. Analysis of Spillover Index Model Result. Subsamples are used to analyze the information spillover effect of variables by the spillover index model. VAR framework is constructed, and the variance of prediction error is calculated by generalized variance decomposition, as shown in Table 4 . The results are consistent with the dependency structure under the vine copula model. Before the trade war, there was a relatively strong information spillover within a single financial market, specifically between the USD/CNY and $\mathrm{HKD} / \mathrm{CNY}$, while the cross-market information spillover was weak. The Sino-US trade war not only led to an increase in information spillover within the stock market but also strengthened the information spillover between the stock market and the exchange rate. The information overflow of the USD/CNY and the HKD/CNY to other indicators has obviously been weakened. When external shocks occur, the exchange rate fluctuates directly and violently, which is very easy to have adverse effects on other markets. Therefore, the government will implement macro adjustment policies to maintain market stability. Under the effect of countercyclical adjustment, the impact of the exchange rate on the stock market is significantly reduced. However, the fluctuation caused by the impact on the stock market will be transmitted to the exchange rate market uncontrollably.

Static analysis can only describe the overall state of information overflow between the two markets. It cannot show the time-varying effect and direction change of information overflow dynamically. Therefore, we use a 200-day rolling window period to calculate the error variance under the 10-day forecast period and carry out generalized variance decomposition. Finally, we obtain the dynamic changes in the two markets' information spillover effect.

First is the information overflow of the mainland stock market and RMB exchange rate, as shown in Figure 4. Overall, the net spillover between the RMB exchange rate and the mainland stock market is roughly within $7 \%$. Compared with the exchange rates of the US dollar and Hong Kong dollar, the directional changes of the RMB Index and Shanghai and Shenzhen stock markets are more frequent. Specifically, the net spillover of the USD/CNY and the mainland stock market tends to be consistent with the HKD/ 
TABLE 3: R-vine copula estimation result of Sino-US trade war.

\begin{tabular}{|c|c|c|c|c|c|c|c|}
\hline & Tree 1 & Copula function & Par1 & Par2 & Kendall & Upper TD & Lower TD \\
\hline \multirow{4}{*}{ Before the trade war } & HKD/CNY, USD/CNY & Student $t$ & 0.99 & 2 & 0.91 & 0.91 & 0.91 \\
\hline & HKD/CNY, RMB Index & Student $t$ & 0.19 & 5.24 & 0.12 & 0.08 & 0.08 \\
\hline & CSI300, HKD/CNY & Joe & 1.11 & - & 0.06 & 0.13 & - \\
\hline & HSI, CSI300 & Gaussian & 0.52 & - & 0.35 & - & - \\
\hline \multirow{4}{*}{ During the trade war } & USD/CNY, HKD/CNY & Student $t$ & 0.98 & 2 & 0.86 & 0.86 & 0.86 \\
\hline & HSI, USD/CNY & Gaussian & -0.16 & - & -0.1 & - & - \\
\hline & HSI, RMB Index & Survival BB1 & 0.14 & 1.19 & 0.21 & 0.01 & 0.21 \\
\hline & HSI, CSI300 & Gaussian & 0.71 & - & 0.51 & - & - \\
\hline
\end{tabular}

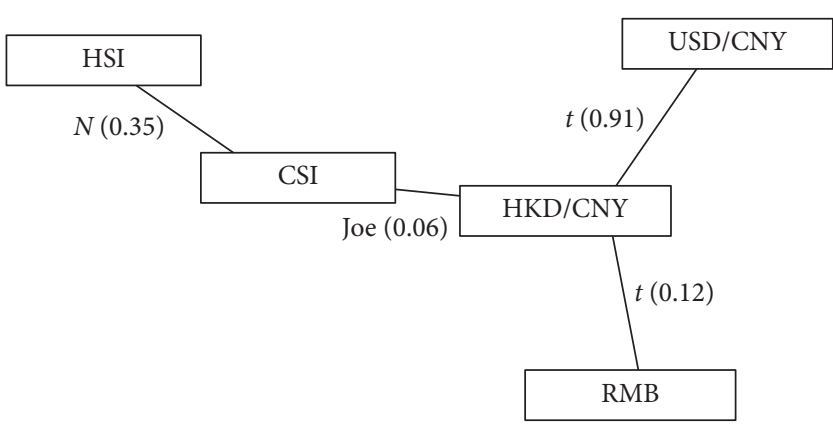

(a)

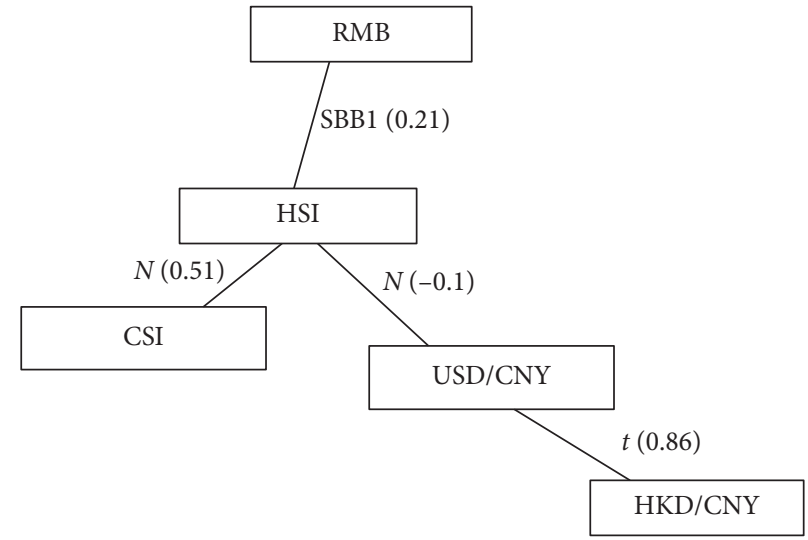

(b)

Figure 3: Tree structure diagram based on R-vine copula. (a) “Tree 1" of R-vine structure before the trade war. (b) "Tree 1" of R-vine structure during the trade war.

TABLE 4: Information spillover values of subsample under static conditions.

\begin{tabular}{|c|c|c|c|c|c|c|c|c|c|c|c|c|c|}
\hline \multicolumn{7}{|c|}{ Before the trade war } & \multicolumn{7}{|c|}{ During the trade war } \\
\hline & USD & $\mathrm{HKD}$ & $\mathrm{RMB}$ & CSI & HSI & From & & USD & $\mathrm{HKD}$ & $\mathrm{RMB}$ & CSI & HSI & From \\
\hline USD & 43.54 & 42.56 & 9.06 & 2.06 & 2.77 & 56.5 & USD & 38.31 & 35.99 & 15.51 & 2.99 & 7.20 & 61.7 \\
\hline HKD & 42.37 & 43.68 & 9.52 & 1.80 & 2.62 & 56.3 & HKD & 37.65 & 40.68 & 14.33 & 2.20 & 5.14 & 59.3 \\
\hline $\mathrm{RMB}$ & 1.86 & 2.41 & 91.64 & 1.89 & 2.19 & 8.4 & RMB & 0.87 & 0.91 & 82.52 & 6.85 & 8.85 & 17.5 \\
\hline CSI & 0.88 & 0.69 & 1.50 & 73.38 & 23.56 & 26.6 & CSI & 0.33 & 0.36 & 5.27 & 63.19 & 30.85 & 36.8 \\
\hline HSI & 0.93 & 0.72 & 1.70 & 23.16 & 73.48 & 26.5 & HSI & 0.66 & 0.68 & 6.73 & 29.96 & 61.98 & 38.0 \\
\hline To & 46.1 & 46.4 & 21.8 & 28.9 & 31.1 & 174.3 & To & 39.5 & 37.9 & 41.8 & 42.0 & 52.0 & 213.3 \\
\hline Total contribution & 89.6 & 90.1 & 113.4 & 102.3 & 104.6 & $34.9 \%$ & Total contribution & 77.8 & 78.6 & 124.4 & 105.2 & 114.0 & $42.7 \%$ \\
\hline
\end{tabular}

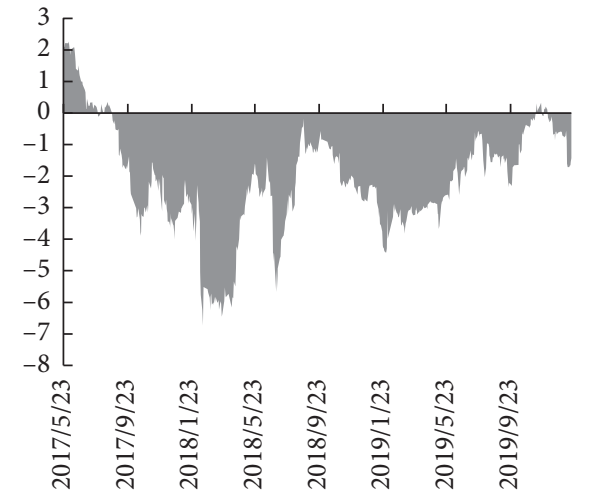

(a)

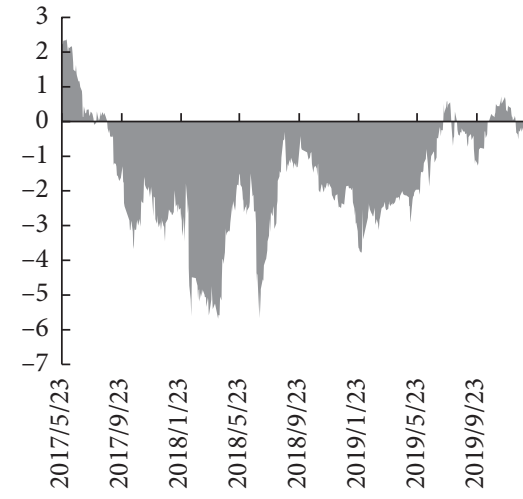

(b)

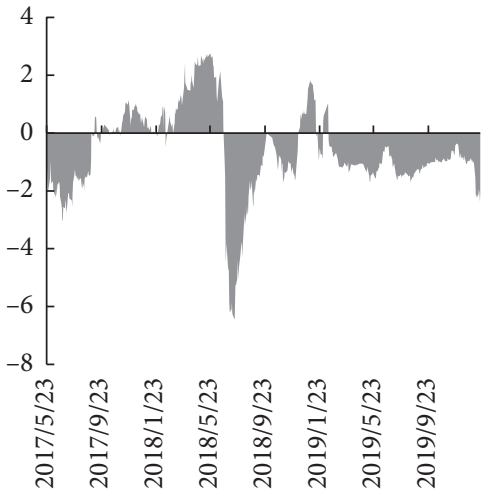

(c)

FIGURE 4: Dynamic changes of net spillover on the exchange rate and mainland stock market. (a) Net spillover of US dollar to RMB and Shanghai and Shenzhen 300 Index. (b) Net spillover of Hong Kong dollar to RMB and Shanghai and Shenzhen 300 Index. (c) Net spillover of RMB Index and Shanghai and Shenzhen 300 Index. 
CNY and the mainland stock market. Before the Sino-US trade war broke out, the USD/CNY had a stronger spillover effect on the stock market. However, the Sino-US trade dispute became prominent and information overflow gradually shifts from the stock market to the exchange rate. The spillover intensity increases significantly. As the Sino-US trade war gradually subsides, the net spillover intensity of the two gradually is weakened. The information spillover is highlighted with the escalation of conflicts and the "tariff war" during the Sino-US trade war. From March to September 2018 and from the beginning of 2019 to May 2019, the two sides impose tariff repression due to trade conflicts and incomplete negotiations. Related industries suffered losses, profits fell, stock prices fell, and stock market fluctuations were transmitted to the exchange rate market. During this period, the information spillover intensity of the stock market to the USD/CNY and HKD/CNY is greatly strengthened and reaches its peak. At the same time, the RMB Index and the stock market overflow are more directional; especially during the trade war, there are many rounds of alternate conversion. In the change of net spillover, the information spillover from the stock market to the RMB Index is more intense. As the RMB tends to be more market-oriented after many reforms, a specific currency cannot fully and effectively reflect market information. The RMB Index is an index formed by referring to the fluctuations of various international currencies and giving different weights, which can reflect the comprehensive changes in the exchange rate market and the strength of the RMB value.

Second is the information overflow of the Hong Kong stock market and RMB exchange rate, as shown in Figure 5. The net spillover of the RMB exchange rate and the Hong Kong stock market is within 7\% except for USD/ CNY and the stock market reaching $11 \%$. The information spillover of the USD/CNY and Hong Kong stock market is highly similar to the HKD/CNY and the Hong Kong stock market. Both of them have weak net spillover to the stock market before the Sino-US trade war broke out, while in the whole period of the trade war, especially in the first half of 2019, there was the high-frequency spillover from the Hong Kong stock market to USD/CNY and HKD/ CNY. Excluding the difference in coordinates, the net spillover strength of Hong Kong stocks to the US dollar exchange rate is higher than that to the Hong Kong dollar exchange rate, indicating that Hong Kong stocks are relatively more sensitive to changes in US dollar exchange rate. In the alternate overflow between Hong Kong stocks and RMB Index, the net overflow intensity of the RMB Index to Hong Kong stocks is higher than that of Hong Kong stocks to the RMB Index. The spillover from the RMB Index to the Hong Kong stock market mainly occurred at the stage of expansion and escalation of the Sino-US trade war. As the contradiction between the two parties could not be eased, the value of the RMB was unstable. Hong Kong Hang Seng Index is mainly composed of large companies in Hong Kong and the mainland, whose businesses are mainly in the mainland and are greatly influenced by mainland policies. Moreover, more than half of the performance of the Hang Seng Index comes from listed companies disclosed in RMB, with companies disclosed in US dollars and Hong Kong dollars accounting for $20 \%$ each. The absolute advantage in quantity causes the Hang Seng Index to be strongly influenced by the RMB exchange rate, especially in the high-frequency period of exchange rate fluctuations, which will be significantly strengthened. The information overflow from Hong Kong stocks to the RMB Index mainly occurs in the second half of 2019. Influenced by the violence in Hong Kong, as a social disorder is caused by the nuisance actions of activists such as rallies, marches, and strikes, the large-scale shutdown of enterprises damages the economic vitality. The falling fluctuation of the stock price is bound to affect the RMB exchange rate.

The third is to consider the spillover effect of both changes mentioned above. The intensity of net information spillovers across markets is floating within $10 \%$. The intensity of spillovers during the Sino-US trade war is significantly enhanced. The direction of information spillover between the USD/CNY, $\mathrm{HKD} / \mathrm{CNY}$, and the stock market is basically from the stock market to the exchange rate. There is also a spillover effect from the exchange rate to the stock market before the trade war. The direction of the information overflow between RMB Index and the stock market has the feature of alternating conversion. Whether it is the mainland stock market or Hong Kong stock market, the overflow direction and period are the same. However, the information overflow between the exchange rate and the mainland stock market is also different from that of the exchange rate and the Hong Kong stock market. Firstly, in terms of spillover intensity, the net information spillover intensity of the RMB Index to Hong Kong stocks is higher than that of mainland stock markets, and the net spillover of mainland stock markets to the RMB Index is higher than that of Hong Kong stocks to RMB Index. The capital of the Hong Kong stock market mainly comes from the mainland capital, outward capital, and local capital, which are related to the RMB exchange rate. Therefore, Hong Kong stocks are greatly affected by the RMB Index, but the influence of Hong Kong stocks on the RMB exchange rate is relatively limited. Secondly, in the direction of spillover, the causality between the exchange rate and the stock market is uncertain. Specifically, there is a net information spillover from the HKD/CNY to the mainland stock market in the second half of 2019. But there is also a reverse situation, and the net spillover direction is from the Hong Kong stock market to HKD/CNY in this period. This is due to the agreement reached in the first phase of the trade agreement between China and the United States. The domestic market gradually gets rid of the pressure and influence, and the stock market gradually shows a stable trend. However, Hong Kong is in a semiparalyzed state due to riots. The stock market fluctuated sharply when the economy was hit hard, becoming the source of potential risk transmission. 


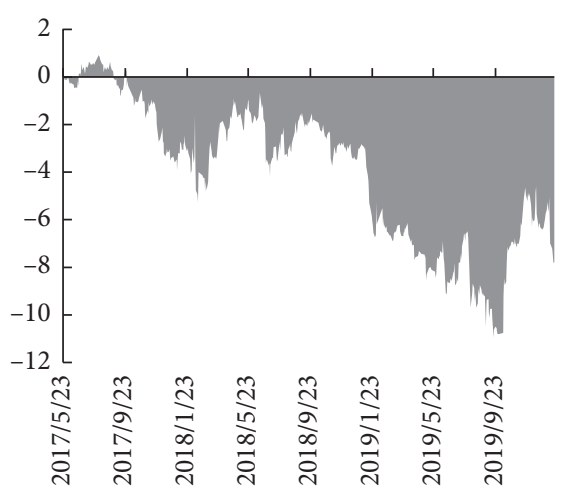

(a)

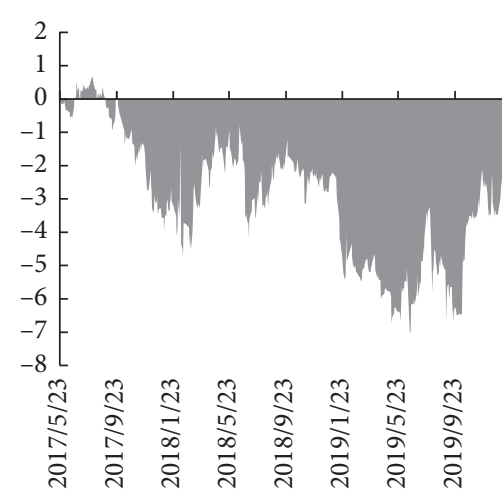

(b)

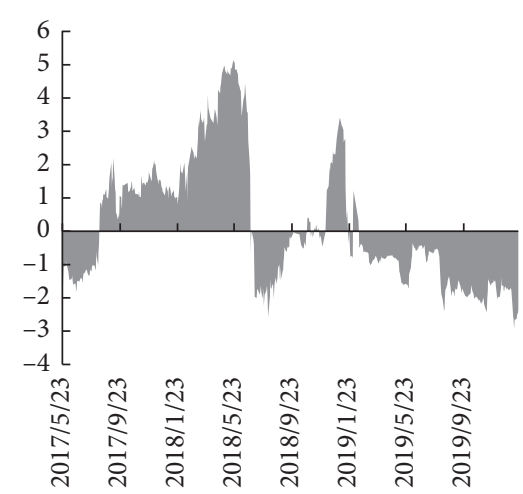

(c)

FIGURE 5: Dynamic changes of net spillover on the exchange rate and Hong Kong stock market. (a) Net overflow of US dollar against RMB and Hong Kong Hang Seng Index. (b) Hong Kong dollar against RMB and Hong Kong Hang Seng Index. (c) Net overflow of RMB Index and Hong Kong Hang Seng Index.

\section{Conclusions}

The vine copula model based on R-vine is constructed for the five representative indexes of the RMB exchange rate and China's stock market in different periods, obtaining the characteristic changes of the dependence structure between $\mathrm{RMB}$ exchange rate and the stock market. The information spillover index model is used to explore the transmission direction and intensity of information spillover between the two markets. It can show the changes in information spillover under the Sino-US trade war comprehensively and dynamically.

First, during the Sino-US trade war, the correlation between RMB exchange rates is decreased and the information spillover of USD/CNY and HKD/CNY is weakened. At the stage of accelerating RMB devaluation, in order to prevent the risk spread caused by its continuous devaluation, the state restarts the countercyclical factor and risk reserve to effectively alleviate the procyclical fluctuation of the exchange rate. In this process, the information spillover effect of the RMB exchange rate on the stock market is weakened to prevent the large-scale spread of potential risks. Therefore, the regulatory authorities should choose the opportunity to use foreign exchange management tools. When the foreign exchange fluctuation is abnormal or the market exhibits irrational behavior, the adjustment tools of foreign exchange regulation such as countercyclical factors will be used to restrain the procyclical sentiment of the market. However, the "herding effect" is not a normal feature of the foreign exchange market, and the irrational behavior of investors will not always exist. Regulators should always pay attention to the changes in the exchange rate market. The essence of countercyclical regulation and macroprudence is that the government participates in the management of the intermediate price, which will restrict the free flow of capital to a certain extent and be used timely and reasonably. When the market returns to rationality, we should adjust or cancel these regulatory measures and restore the market-led mechanism.

Second, the Sino-US trade war will enhance the correlation and information spillover between the stock market and the RMB exchange rate. The results of $\mathrm{R}$-vine structure show that the central Hong Kong stock market has a strong tail correlation with the RMB Index, which means that risk transmission becomes easier when the market is faced with negative external shocks. When external shocks occur, the market in the central position will shift, and the uncertainty among the financial markets as a whole will increase. The key center position causes the change of the related market through high correlation and asymmetric tail effect. In this process of transmission, international capital flows, foreign trade, psychological expectations, and interest rates are important channels to influence market changes. Therefore, investors and management departments need to pay attention to tail risks. Extreme events such as the trade war and the financial crisis may cause a superimposed effect between the two markets. Establishing a risk prevention and control system between markets could effectively monitor changes in the market under external shocks and predict the future situation in advance. It achieves the purpose of preventing risk spillover and is used to reduce the risk of contagion, avoiding unnecessary losses caused by the decline in investor confidence and market expectations due to problems such as information asymmetry.

Third, the spillover effect of the RMB Index and the stock market is stronger than the single currency exchange rate. It more comprehensively reflects various factors and information such as the actual supply and demand of RMB. From the perspective of spillover intensity, the correlation between the Chinese stock market and the RMB Index is significantly higher than that between the stock market and the single currency exchange rate. From the perspective of spillover direction, the information spillover from the RMB Index to the stock market shows the feature of alternating transformation, while the information spillover from the stock market to USD/CNY and HKD/CNY shows a single direction during the high tide of the trade war. Under the process of market-oriented reform and internationalization, the exchange rate system no longer focuses on a single currency but refers to a basket of currencies, which can better reflect its comprehensive value. Therefore, it is necessary to promote the reform of the RMB exchange rate 
market mechanism. Reasonable selection of macroeconomic indicators improves the selection of the weight of "a basket of currencies" and further reduces the impact of government intervention and policy adjustments on the market. Expanding the rise and fall of foreign exchange and stock markets increases the flexibility of China's financial market. Investors should fully consider the stability and strength of currencies when changing their investment direction.

Fourth, the Hong Kong stock market is more closely linked with the RMB exchange rate due to its higher degree of openness. Comparing the mainland stock market and the Hong Kong stock market, it is found that the correlation and spillover effects of the RMB exchange rate on the Hong Kong stock market are generally higher than those on the mainland stock market. Although the degree of financial market opening in mainland China has improved in recent years, it is still relatively closed compared with the Hong Kong market. As a mature and open market, the Hong Kong stock market has great advantages in absorbing foreign capital, introducing management methods, and promoting market integrity. However, it is also vulnerable to fluctuations in other markets and becomes an emission area for external risks. Therefore, we should emphasize on macroprudential supervision while increasing the degree of openness. Dynamic financial regulation through the market fills the gaps in overseas assets and strengthens the necessary review and restriction of international capital. It can prevent the impact of speculative capital, promote long-term stable capital entry into the market, and reduce the vulnerability of overseas capital markets.

The information spillover between the RMB exchange rate and the stock market is closely related to the degree of market openness. There is a positive relationship between the opening of the market and the ability to receive external information. The occurrence of external shocks is easy to accelerate the information transmission of the market, and the risk will continue to spread in this process, which will endanger the stability of the entire financial system. Therefore, while promoting the internationalization of the financial market, it is also necessary to establish a "risk firewall" to effectively avoid risk contagion and control risk spread. Investors timely adjust the allocation of different assets and investment strategies to improve risk tolerance, which involves factors such as the rate of return, liquidity, and transaction costs.

\section{Data Availability}

The data used to support the findings of this study are available from the corresponding author upon request. The empirical data are from the Choice database.

\section{Conflicts of Interest}

The authors declare that there are no conflicts of interest regarding the publication of this paper.

\section{Acknowledgments}

Project of Basic Scientific Research Business Expenses of Central Universities (Grant no. 2232020B-02) and Project of
Basic Scientific Research of Central Universities (Grant no. CUSF-DH-D-2016062).

\section{Supplementary Materials}

The attached data file is the logarithmic return rate of the stock market and exchange rate. (Supplementary Materials)

\section{References}

[1] $\mathrm{H}$. Joe and T. Hu, "Multivariate distributions from mixtures of max-infinitely divisible distributions," Journal of Multivariate Analysis, vol. 57, no. 2, pp. 240-265, 1996.

[2] F. X. Diebold and K. Yilmaz, "Measuring financial asset return and volatility spillovers, with application to global equity markets," The Economic Journal, vol. 119, no. 534, pp. 158171, 2009.

[3] F. X. Diebold and K. Yilmaz, "Better to give than to receive: predictive directional measurement of volatility spillovers," International Journal of Forecasting, vol. 28, no. 1, pp. 57-66, 2012.

[4] C.-C. Nieh and C.-F. Lee, "Dynamic relationship between stock prices and exchange rates for G-7 countries," The Quarterly Review of Economics and Finance, vol. 41, no. 4, pp. 477-490, 2001.

[5] C. Tudor and C. Popescu-Dutaa, "On the causal relationship between stock returns and exchange rates changes for 13 developed and emerging markets," Procedia-Social and Behavioral Sciences, vol. 57, pp. 275-282, 2012.

[6] E. Andreou, M. Matsi, and A. Savvides, "Stock and foreign exchange market linkages in emerging economies," Journal of International Financial Markets, Institutions and Money, vol. 27, pp. 248-268, 2013.

[7] B. M. Blau, "The volatility of exchange rates and the nonnormality of stock returns," Journal of Economics and Business, vol. 91, pp. 41-52, 2017.

[8] B. M. Blau, "Exchange rate volatility and the stability of stock prices," International Review of Economics and Finance, vol. 58, pp. 299-311, 2018.

[9] S. Śmiech and M. Papież, "Fossil fuel prices, exchange rate, and stock market: a dynamic causality analysis on the European market," Economics Letters, vol. 118, no. 1, pp. 199-202, 2013

[10] L. Sui and L. Sun, "Spillover effects between exchange rates and stock prices: evidence from BRICS around the recent global financial crisis," Research in International Business and Finance, vol. 36, pp. 459-471, 2016.

[11] J. C. Reboredo, M. A. Rivera-Castro, and A. Ugolini, "Downside and upside risk spillovers between exchange rates and stock prices," Journal of Banking and Finance, vol. 62, pp. 76-96, 2016.

[12] H. Y. Yin, "Risk spillover effect of exchange rate and stock market related industries: based on static and dynamic CoVaR analysis," Journal of Zhongnan University of Economics and Law, vol. 6, pp. 112-121, 2017.

[13] H. Zhao and X. J. Shi, "Research on the influence of exchange rate, interest rate and foreign stock price on Chinese stock price-ECM-T-garch empirical study based on high frequency data," Financial Theory and Practice, vol. 11, pp. 1-8, 2017.

[14] N. S. Yu and P. T. Yu, "An empirical analysis of the relationship between RMB exchange rate and China's stock market composite index and industrial index changes," Statistics and Decision, vol. 34, no. 22, pp. 158-161, 2018. 
[15] A. M. Zhou and F. Han, "Research on risk spillover effect between stock market and foreign exchange market-based on GARCH- time-varying copula-CoVaR model," International Finance Research, vol. 11, pp. 54-64, 2017.

[16] C. Y. Que and J. K. Li, "Asymmetric transmission effect of difference between offshore and offshore RMB exchange rate on offshore stock prices: empirical evidence based on NARDL model," World Economy Study, vol. 10, pp. 33-47, 2018.

[17] C. L. Chen, N. H. Zhang, and C. G. Huang, "Research on dynamic relationship among foreign exchange market, bond market and stock market," International Finance Research, vol. 12, pp. 83-93, 2017.

[18] Z. L. Xiao and Y. L. Yin, "A study on the volatility spillover effect of foreign exchange market, stock market and bond market in China-an empirical analysis based on "811 exchange rate reform"' Financial Theory and Practice, vol. 9, pp. 82-87, 2018.

[19] P. Zhang, "Research on the influence of stock market exchange market interaction on financial market stability under open conditions," Research on Financial Supervision, vol. 10, pp. 69-84, 2019.

[20] D. H. Wang and C. Wang, "Alienation of spillover effect of foreign exchange market and stock market under different market conditions after exchange rate reform," China Journal of Management Sciences, vol. 15, no. 11, pp. 91-103, 2012.

[21] S. Yan and L. W. Li, "Research on the dynamic correlation between China's stock market and foreign exchange market," Macroeconomic Research, vol. 3, pp. 32-40, 2013.

[22] X. C. Hao and Z. Li, "Study on the impact of external shock on China's stock market crash," Nankai Economic Studies, vol. 6, pp. 131-149, 2017.

[23] X. Y. Chen and F. F. Liu, “The impact of RMB's accession to SDR on AH share premium," Investment Research, vol. 36, no. 9, pp. 107-119, 2017.

[24] W. B. Liang and S. R. Zhang, "Research on the impact of RMB exchange rate on A-share market," National Circulation Economy, vol. 26, pp. 82-83, 2018.

[25] Q. Z. Li, X. M. Lin, and Y. Fang, "The impact of high frequency data in financial market on China's short-term international capital flows: an analysis based on Bayesian mixing VAR," Economic Issues Explore, vol. 4, pp. 163-169, 2019. 